Article

\title{
Association between Parent and Child Dietary Sodium and Potassium Intakes: Aomori Prefectural Health and Nutrition Survey, 2016
}

\author{
Tatsuya Koyama *(D) and Nobuo Yoshiike \\ Aomori University of Health and Welfare, 58-1 Mase-Hamadate, Aomori-shi 038-8505, Japan; \\ n_yoshiike@auhw.ac.jp \\ * Correspondence: t_koyama@auhw.ac.jp
}

Received: 29 May 2019; Accepted: 21 June 2019; Published: 23 June 2019

\begin{abstract}
This study investigated the association between parent and child sodium and potassium intakes using data from the 2016 Aomori Prefectural Health and Nutrition Survey. We analyzed one day dietary record data of 103 mothers, 94 fathers, 51 children aged 1-3 years, 39 children aged 4-6 years, 91 children aged 7-14 years, and 56 children aged 15-19 years. We also examined the association of sodium and potassium intake between co-habiting grandparents and their grandchildren. After adjusting for covariates, the total daily sodium intake in mothers was positively associated with that in children for every age group. Potassium intakes by the mothers during breakfast and dinner were positively associated with those in children aged 1-3, 4-6, and 7-14 years. The associations in sodium and potassium intakes between fathers and children were weaker. In addition, these associations were similar to those between the sodium intakes of grandchildren and their grandparents. The association between mother and child sodium and potassium intakes at breakfast and dinner was related to the consumption of similar foods, which suggests the importance of home environment in influencing total dietary sodium and potassium intake in Japanese people.
\end{abstract}

Keywords: child; grandparent; parent; potassium; sodium

\section{Introduction}

Excessive sodium and insufficient potassium intake can lead to hypertension and cardiovascular disease in adults [1,2]. Similarly, sodium and potassium intake are positively and inversely associated with blood pressure, respectively, in children [3,4]. Elevated blood pressure in childhood is a predisposing risk factor for hypertension in adulthood [5,6] and increases the risk of the early development of cardiovascular disease [7].

Although sodium intake in Japanese people has decreased since the 1950s, high sodium intake is still noted in this population [8]. Aomori prefecture is a region with high sodium intake in Japan. For example, according to the National Health and Nutrition Survey 2016 in Japan, the average sodium intake in Aomori prefecture was approximately $4450 \mathrm{mg} /$ person/day, while that in Japan was approximately $4250 \mathrm{mg} /$ day [9]. Aomori prefecture also has a high stroke mortality rate compared to other regions in Japan [10]. It is important to educate children in Japan about the importance of reduction of sodium intake, especially in Aomori prefecture.

While growing evidence suggests that dietary intake among children modestly resembles that of parents, the age of children may be associated with the parent-child dietary resemblance [11]. However, few studies have investigated the association between sodium and potassium intakes of parents and children in Japanese people [12]. While grandparents may influence the dietary intake of co-habiting grandchildren [13], little is known regarding whether the dietary intake among grandchildren resembles 
that of co-habiting grandparents. Most Japanese children attend schools on weekdays. Although Japanese children attend schools on weekdays and school meals may influence their total daily nutrient intake, parents can directly influence their dietary choices. [14].

Therefore, the aim of this study was to assess the association between parent and child sodium and potassium intakes stratified by eating occasion (total day, breakfast, and dinner). We also examined the association of sodium and potassium intake between co-habiting grandparents and their grandchildren.

\section{Materials and Methods}

\subsection{Study Population}

The present cross-sectional study was based on data from the 2016 Aomori Prefectural Health and Nutrition Survey. The full details of this survey are described elsewhere [15]. The survey was conducted in the same way as the National Health and Nutrition Survey in Japan [9]. Twelve census units in Aomori prefecture were randomly sampled as a survey area based on the population census. All non-institutionalized Japanese people aged $\geq 1$ year living in these areas were invited to participate. The survey was conducted between October and November 2016. A total of 846 participants completed the dietary survey.

We included children 1-19 years of age with the complete 1 day dietary record data. Parents and grandparents were matched to the children by family relationship. After matching parents with their children, the final sample sizes were 197 parent-child (94 father-child and 103 mother-child) and 40 grandparent-grandchild pairs.

The survey was conducted according to the principles of the Declaration of Helsinki, and written informed consent was obtained from all individual subjects and their parents. The Aomori Prefectural Health and Nutrition Survey had stringent protocols and procedures to ensure confidentiality and to protect individual participants from identification. This survey was conducted according to the regulations of Aomori Prefecture. Additionally, the present secondary analysis was based on a contract research agreement and the public-use dataset consisting of only anonymized information. Thus, institutional review board approval was not required.

\subsection{Assessment of Dietary Intake}

Dietary intake data were collected using a 1 day semi-weighed household dietary record, the procedure of which has been described elsewhere [16]. Briefly, the participants and the main record-keeper were provided both written and verbal instructions by trained fieldworkers (registered dietitians) regarding the purpose of the dietary records and how to weigh and record the food items consumed by household members each day. When household members shared food from the same dish, the record-keeper was also asked to record the approximate proportions of food taken by each member so that the dietary intakes of each individual could be calculated. When weighing was not possible (e.g., eating out), the record-keeper was asked to record as much information as possible, including the portion size consumed and details of any leftovers. Children aged 7 to 14 years had lunch at school. School lunch was nutritionally managed based on the Criteria for Provision of School Lunch of the School lunch Act. School lunch was served so that salt intake was low and potassium intake was high by providing high vegetable and milk [17]. The recording day was freely selected by each household, except for Sundays, national holidays, and days with special events (e.g., weddings or funerals). Trained fieldworkers visited the household and checked the completeness of food recording and, when necessary, additional information was added. The estimated salt intake for each individual was calculated from the record of household food consumption and, for shared dishes or foods, approximate proportions consumed by each household member based on the Standard Table of Food Composition in Japan [18]. 


\subsection{Statistical Analysis}

We categorized the children into four age groups (1-3, 4-6, 7-14, and 15-19 years). All analyses were separated by eating occasion (daily total, breakfast, and dinner). We used descriptive statistics to summarize participants' characteristics as means and standard deviations for continuous variables. Multiple linear regression was used to assess the association between child dietary intake (dependent variable) and parent dietary intake (independent variable). For children aged 1-3 and 4-6 years, we adjusted for parent age. For children aged 7-14 years, we adjusted for parent and child sex and age. For children aged 15-19 years, we adjusted for parent age and child sex.

The association between the energy-adjusted dietary intake of grandchildren and that of their grandparents was also examined using Spearman correlations. In this study, all grandparent-grandchild pairs were living together. Energy adjustments were made using density methods. The energy-adjusted total daily intakes of sodium and potassium were determined by dividing the total daily sodium and potassium intakes by the total daily energy intake. Since there were only three pairs of grandparent-grandchildren aged 4-6 years, we did not show these data.

All statistical analyses were performed using SPSS version 24.0 (IBM Corporation, Tokyo, Japan). All reported $p$-values were two-tailed, and $p$-values $<0.05$ were considered statistically significant.

\section{Results}

On average, the sodium intake at breakfast accounted for 19-29\%, while dinner accounted for $31-50 \%$ of the intake (Table 1). Similarly, on average, the potassium intake at breakfast and dinner accounted for $20-29 \%$ and $29-52 \%$ of the intake.

A $1 \mathrm{mg} /$ day increase in the mother's sodium intake was associated with a $0.4-1.4 \mathrm{mg} / \mathrm{day}$ increase in child's salt intake (Table 2). This association was observed for both breakfast and dinner. The potassium intakes at breakfast and dinner for mothers were positively associated with those for children in all four age groups, except for dinner in children aged 15-19 years. Compared with that of mother-child, the father-child association appeared to be weaker.

There were significant positive correlations in energy-adjusted total daily sodium intake between grandparents and grandchildren aged 1-3 years (Table 3). There were significant positive correlations in energy-adjusted total daily intakes of sodium and potassium between grandparents and grandchildren aged 7-14 years. Finally, there were significant positive correlations in energy-adjusted intakes of sodium and potassium during breakfast and dinner between grandparents and grandchildren aged $15-19$ years. 
Table 1. Dietary intakes of children, mothers, fathers, and grandparents.

\begin{tabular}{|c|c|c|c|c|c|c|c|c|c|c|c|c|c|c|}
\hline \multirow{3}{*}{$\begin{array}{c}\text { Dietary Intakes } \\
\text { Men }\end{array}$} & \multicolumn{8}{|c|}{ Children } & \multirow{2}{*}{\multicolumn{2}{|c|}{$\begin{array}{l}\text { Mothers } \\
(n=103)\end{array}$}} & \multirow{2}{*}{\multicolumn{2}{|c|}{$\begin{array}{l}\text { Fathers } \\
(n=94)\end{array}$}} & \multirow{2}{*}{\multicolumn{2}{|c|}{$\begin{array}{l}\text { Grandparents } \\
\qquad(n=40)\end{array}$}} \\
\hline & \multicolumn{2}{|c|}{$\begin{array}{c}1-3 \text { Years } \\
(n=51)\end{array}$} & \multicolumn{2}{|c|}{$\begin{array}{c}4-6 \text { Years } \\
(n=39)\end{array}$} & \multicolumn{2}{|c|}{$\begin{array}{c}7-14 \text { Years } \\
(n=91)\end{array}$} & \multicolumn{2}{|c|}{$\begin{array}{c}\text { 15-19 Years } \\
(n=56)\end{array}$} & & & & & & \\
\hline & 24 & $47 \%$ & 17 & $44 \%$ & 44 & $48 \%$ & 25 & $45 \%$ & 103 & $100 \%$ & 0 & $0 \%$ & 16 & $40 \%$ \\
\hline Age (years) & 1.8 & $(0.9)$ & 5.0 & $(0.7)$ & 10.5 & $(2.4)$ & 16.4 & (1.3) & 38.9 & (7.1) & 40.2 & $(7.8)$ & 71.2 & (8.1) \\
\hline \multicolumn{15}{|l|}{ Energy (kcal) } \\
\hline Daily total & 1083 & (209) & 1356 & (239) & 1849 & (362) & 2128 & (550) & 1641 & (402) & 2094 & (525) & 1880 & (583) \\
\hline Breakfast & 264 & (72) & 348 & (127) & 459 & (150) & 466 & (244) & 399 & (220) & 417 & (265) & 499 & (211) \\
\hline Dinner & 335 & (134) & 446 & (201) & 645 & (234) & 824 & (199) & 670 & (236) & 910 & (277) & 815 & (333) \\
\hline \multicolumn{15}{|l|}{ Sodium (mg) } \\
\hline Daily total & 2002 & (871) & 2669 & (966) & 3519 & (1078) & 3765 & (947) & 3631 & (1544) & 3941 & (1603) & 4119 & (1529) \\
\hline Breakfast & 534 & (334) & 615 & (466) & 918 & $(602)$ & 785 & (515) & 940 & $(854)$ & 753 & $(640)$ & 1176 & (1050) \\
\hline Dinner & 630 & (539) & 1080 & (687) & 1284 & (595) & 1891 & (825) & 1574 & (901) & 1771 & (881) & 1916 & $(745)$ \\
\hline \multicolumn{15}{|l|}{ Potassium (mg) } \\
\hline Daily total & 1400 & (517) & 1471 & (398) & 2085 & (651) & 2062 & (558) & 1935 & $(652)$ & 1949 & (750) & 2346 & (1169) \\
\hline Breakfast & 323 & (190) & 297 & (160) & 458 & (269) & 482 & (319) & 473 & (332) & 407 & (326) & 682 & $(488)$ \\
\hline Dinner & 411 & (249) & 486 & (240) & 803 & (412) & 892 & (376) & 844 & (362) & 1014 & (410) & 1007 & (501) \\
\hline
\end{tabular}

Values are shown as number (\%) or mean (standard deviation).

Table 2. Association between parent-child sodium and potassium intakes.

\begin{tabular}{|c|c|c|c|c|c|c|c|c|c|c|}
\hline \multirow{2}{*}{ Dietary Intake } & \multirow{2}{*}{ Child } & \multirow{2}{*}{ Eating Occasion } & \multicolumn{4}{|c|}{ Mother } & \multicolumn{4}{|c|}{ Father } \\
\hline & & & $n$ & $\beta$ & $(95 \% \mathrm{CI})$ & $P$ & $n$ & $\beta$ & $(95 \% \mathrm{CI})$ & $P$ \\
\hline \multirow{12}{*}{$\begin{array}{l}\text { Sodium } \\
\text { (mg) }\end{array}$} & \multirow{3}{*}{$\begin{array}{c}\text { Child } \\
\text { (1-3 years) }\end{array}$} & Daily total & 21 & 1.35 & $(0.67-2.04)$ & 0.001 & 21 & 0.19 & $(-0.11-0.48)$ & 0.198 \\
\hline & & Breakfast & 21 & 1.81 & $(0.78-2.83)$ & 0.002 & 21 & 0.61 & $(0.30-0.91)$ & 0.001 \\
\hline & & Dinner & 21 & 0.72 & $(0.19-1.24)$ & 0.010 & 21 & 0.09 & $(-0.23-0.23)$ & 0.412 \\
\hline & \multirow{3}{*}{$\begin{array}{c}\text { Child } \\
\text { (4-6 years) }\end{array}$} & Daily total & 20 & 0.39 & $(0.16-0.63)$ & 0.003 & 16 & 0.39 & $(0.10-0.68)$ & 0.012 \\
\hline & & Breakfast & 20 & 0.22 & $(0.01-0.43)$ & 0.044 & 16 & 0.50 & $(0.27-0.73)$ & $<0.001$ \\
\hline & & Dinner & 20 & 0.73 & $(0.49-0.97)$ & $<0.001$ & 16 & 0.85 & $(0.42-1.28)$ & 0.001 \\
\hline & \multirow{3}{*}{$\begin{array}{c}\text { Child } \\
\text { (7-14 years) }\end{array}$} & Daily total & 40 & 0.60 & $(0.40-0.80)$ & $<0.001$ & 36 & 0.29 & $(0.04-0.55)$ & 0.024 \\
\hline & & Breakfast & 40 & 0.42 & $(0.15-0.70)$ & 0.003 & 36 & 0.28 & $(-0.08-0.63)$ & 0.120 \\
\hline & & Dinner & 40 & 0.72 & $(0.48-0.95)$ & $<0.001$ & 36 & 0.30 & $(0.12-0.48)$ & 0.002 \\
\hline & \multirow{3}{*}{$\begin{array}{c}\text { Child } \\
\text { (15-19 years) }\end{array}$} & Daily total & 22 & 0.39 & $(0.09-0.69)$ & 0.014 & 21 & 0.15 & $(-0.15-0.45)$ & 0.317 \\
\hline & & Breakfast & 22 & 0.40 & $(0.08-0.72)$ & 0.017 & 21 & 0.03 & $(-0.35-0.41)$ & 0.852 \\
\hline & & Dinner & 22 & 0.61 & $(0.48-0.74)$ & $<0.001$ & 21 & 0.74 & $(0.44-1.03)$ & $<0.001$ \\
\hline
\end{tabular}


Table 2. Cont.

\begin{tabular}{|c|c|c|c|c|c|c|c|c|c|c|}
\hline \multirow{2}{*}{ Dietary Intake } & \multirow{2}{*}{ Child } & \multirow{2}{*}{ Eating Occasion } & \multicolumn{4}{|c|}{ Mother } & \multicolumn{4}{|c|}{ Father } \\
\hline & & & $n$ & $\beta$ & $(95 \% \mathrm{CI})$ & $P$ & $n$ & $\beta$ & $(95 \%$ CI $)$ & $P$ \\
\hline \multirow{12}{*}{$\begin{array}{l}\text { Potassium } \\
\quad(\mathrm{mg})\end{array}$} & \multirow{3}{*}{$\begin{array}{c}\text { Child } \\
\text { (1-3 years) }\end{array}$} & Daily total & 21 & 0.15 & $(-0.57-0.86)$ & 0.674 & 21 & -0.12 & $(-0.41-0.17)$ & 0.396 \\
\hline & & Breakfast & 21 & 1.14 & $(0.33-1.94)$ & 0.008 & 21 & 0.43 & $(0.27-0.60)$ & $<0.001$ \\
\hline & & Dinner & 21 & 0.98 & $(0.53-1.43)$ & $<0.001$ & 21 & 0.42 & $(0.08-0.77)$ & 0.018 \\
\hline & \multirow{3}{*}{$\begin{array}{c}\text { Child } \\
\text { (4-6 years) }\end{array}$} & Daily total & 20 & 0.89 & $(-0.22-0.40)$ & 0.546 & 16 & -0.35 & $(-0.81-0.11)$ & 0.123 \\
\hline & & Breakfast & 20 & 0.39 & $(0.13-0.85)$ & 0.006 & 16 & 0.25 & $(-0.10-0.59)$ & 0.144 \\
\hline & & Dinner & 20 & 0.53 & $(0.08-0.97)$ & 0.023 & 16 & -0.20 & $(-0.85-0.46)$ & 0.532 \\
\hline & \multirow{3}{*}{$\begin{array}{c}\text { Child } \\
\text { (7-14 years) }\end{array}$} & Daily total & 40 & 0.41 & $(0.06-0.77)$ & 0.023 & 36 & 0.24 & $(-0.03-0.52)$ & 0.080 \\
\hline & & Breakfast & 40 & 0.43 & $(0.06-0.80)$ & 0.024 & 36 & 0.06 & $(-0.29-0.42)$ & 0.721 \\
\hline & & Dinner & 40 & 0.68 & $(0.30-1.05)$ & 0.001 & 36 & 0.11 & $(-0.17-0.40)$ & 0.422 \\
\hline & \multirow{3}{*}{$\begin{array}{c}\text { Child } \\
\text { (15-19 years) }\end{array}$} & Daily total & 22 & 0.41 & $(-0.03-0.86)$ & 0.066 & 21 & 0.21 & $(-0.16-0.58)$ & 0.241 \\
\hline & & Breakfast & 22 & -0.18 & $(-1.04-0.68)$ & 0.863 & 21 & 0.53 & $(-0.36-0.46)$ & 0.788 \\
\hline & & Dinner & 22 & 0.49 & $(0.20-0.79)$ & 0.003 & 21 & 0.65 & $(0.20-1.11)$ & 0.007 \\
\hline
\end{tabular}

Child (1-3 years), child (4-6 years): adjusted for age of parent. Child (7-14 years): adjusted for age of parent, sex, and age of child. Child (15-19 years): adjusted for age of parent, and sex of child.

Table 3. Grandparent-grandchild correlations in sodium and potassium intake.

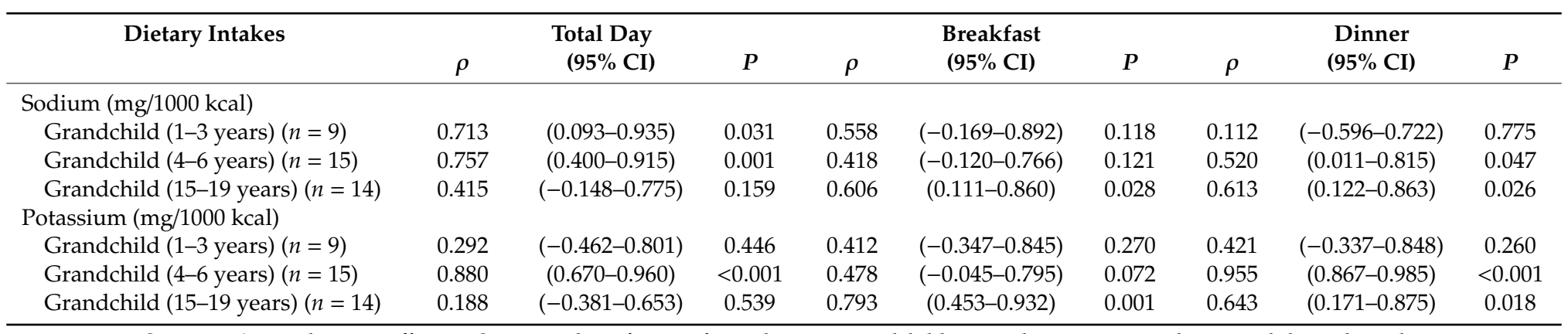

$\rho$, Spearman's correlation coefficient. Since number of pairs of grandparent-grandchildren aged 4-6 years was three, we did not show data. 


\section{Discussion}

Our results demonstrate that the sodium intake of parents, especially mothers, was positively associated with that of children for most age groups. In addition, these results were consistent with the association between the sodium intakes of grandchildren and their grandparents. The potassium intakes of the mothers at breakfast and dinner were positively associated with those of their children. These findings are similar to those of previous studies. The Framingham Heart Study (FHS) [19] and the Salt and Other Nutrient Intakes in Children (SONIC) study [20] reported a correlation between mother and child's sodium intakes but not in father's sodium intake or in either parent's potassium intakes. Mothers usually devote more time to childcare [21]. Women are more likely to have the primary responsibility for meal planning, shopping, and preparation [22,23]. Moreover, long working hours among fathers are positively associated with take-out meals, missed family meals, and eating while working [24]. The increased association between mother and children is likely explained by these observations. Family meals are positively associated with a parent-child association [25]. The association between grandparents and their grandchildren may be explained by family meals.

Service et al. explained the different association between sodium and potassium intakes by a similarity in dietary sources [19]. The major sources of sodium in children's and adults' diets were similar, while the dietary sources of potassium differed between adults and children. However, to our knowledge, there are no data about dietary sources of sodium and potassium in Japanese children. Our results showed that the proportion of potassium intake at lunch was larger than that of sodium intake at lunch for children. This may explain the lack of association between the total daily potassium intakes in parents and children.

Taste preferences for sodium are determined by exposure to salty foods; both short-term and lifelong exposures to higher sodium intake may lead to a preference for higher-sodium foods [26-29]. Given that taste and dietary preferences appear to develop and track over life, it is important that childhood sodium intake is not excessive [30]. Parents may play an important role in the reduction of sodium intake of children by reducing seasoning during cooking and choosing lower-sodium manufactured products, thereby reducing the threshold of salt taste early in life.

This study had several limitations. First, our results may not be generalizable to the Japanese population because the number of participants, especially children aged 1-3 and 4-6 years, was small, and the study was conducted in only one prefecture. Sodium intake in Aomori prefecture is higher than the national average in Japan [9]. The prevalence of obesity in children is also higher in Aomori prefecture [31]. Although this study was done in one area of Japan, it is an important area in considering Japanese health problems. Moreover, sodium and potassium intakes were estimated using a one day dietary record. Considering that dietary intake varies day-to-day among free-living individuals, the dietary patterns revealed in this study from one day weighed household dietary record do not likely represent the usual patterns of the individual respondents. In this study, the estimated intakes of sodium and potassium did not compare to $24 \mathrm{~h}$ urinary and potassium excretion. Therefore, the validity of the household dietary records was unknown.

\section{Conclusions}

The results of this study indicate an association between mother and child sodium intakes in total daily and potassium intake at breakfast and dinner in Japanese people. This finding suggests that family-based interventions are more likely to have greater effects in reducing sodium intake and increasing potassium intake in families with children, which will assist in reducing the risk of cardiovascular disease later in life.

Author Contributions: T.K. analyzed the data and wrote the article. N.Y. substantially consolidated the data. All authors critically revised the article and approved the final manuscript.

Funding: This work was supported in part by the Health and Labour Sciences Research Grant (No. H29-jyunkankitouippan-006) from the Ministry of Health, Labour and Welfare, Japan. The Ministry of Health, Labour and Welfare had no role in the design, analysis or writing of this article. 
Conflicts of Interest: The authors declare no conflict of interest.

\section{References}

1. Aaron, K.J.; Sanders, P.W. Role of dietary salt and potassium intake in cardiovascular health and disease: A review of the evidence. Mayo. Clin. Proc. 2013, 88, 987-995. [CrossRef] [PubMed]

2. Aburto, N.J.; Ziolkovska, A.; Hooper, L.; Elliott, P.; Cappuccio, F.P.; Meerpohl, J.J. Effect of lower sodium intake on health: Systematic review and meta-analyses. BMJ 2013, 346, f1326. [CrossRef]

3. He, F.J.; MacGregor, G.A. Importance of salt in determining blood pressure in children: Meta-analysis of controlled trials. Hypertension 2006, 48, 861-869. [CrossRef] [PubMed]

4. Geleijnse, J.M.; Grobbee, D.E.; Hofman, A. Sodium and potassium intake and blood pressure change in childhood. BMJ 1990, 300, 899-902. [CrossRef] [PubMed]

5. Chen, X.; Wang, Y. Tracking of blood pressure from childhood to adulthood: A systematic review and meta-regression analysis. Circulation 2008, 117, 3171-3180. [CrossRef] [PubMed]

6. Tirosh, A.; Afek, A.; Rudich, A.; Percik, R.; Gordon, B.; Ayalon, N.; Derazne, E.; Tzur, D.; Gershnabel, D.; Grossman, E.; et al. Progression of normotensive adolescents to hypertensive adults: A study of 26,980 teenagers. Hypertension 2010, 56, 203-209. [CrossRef]

7. Berenson, G.S. Childhood risk factors predict adult risk associated with subclinical cardiovascular disease. The Bogalusa Heart Study. Am. J. Cardiol. 2002, 90, 3L-7L. [CrossRef]

8. Uechi, K.; Sugimoto, M.; Kobayashi, S.; Sasaki, S. Urine 24-Hour Sodium Excretion Decreased between 1953 and 2014 in Japan, but Estimated Intake Still Exceeds the WHO Recommendation. J. Nut. 2017, 147, 390-397. [CrossRef]

9. Ministry of Health, Labor and Welfare. The national health and nutrition survey in Japan 2016. Available online: https://www.mhlw.go.jp/bunya/kenkou/eiyou/dl/h28-houkoku.pdf (accessed on 18 September 2018).

10. Ministry of Health, Labor and Welfare. Life table in prefectures 2015. Available online: https://www.mhlw. go.jp/toukei/saikin/hw/life/tdfk15/dl/tdfk15-11.pdf (accessed on 18 September 2018).

11. Wang, Y.; Beydoun, M.A.; Li, J.; Liu, Y.; Moreno, L.A. Do children and their parents eat a similar diet? Resemblance in child and parental dietary intake: Systematic review and meta-analysis. J. Epidemiol. Community Health 2011, 65, 177-189. [CrossRef]

12. Ohta, Y.; Iwayama, K.; Suzuki, H.; Sakata, S.; Hayashi, S.; Iwashima, Y.; Takata, A.; Kawano, Y. Salt intake and eating habits of school-aged children. Hypertens. Res. 2016, 39, 812-817. [CrossRef]

13. Young, K.G.; Duncanson, K.; Burrows, T. Influence of grandparents on the dietary intake of their 2-12-year-old grandchildren: A systematic review. Nutr. Diet 2018, 75, 291-306. [CrossRef] [PubMed]

14. Birch, L.L.; Fisher, J.O. Development of eating behaviors among children and adolescents. Pediatrics 1998, 101, 539-549. [PubMed]

15. Aomori Prefecture: Aomori Prefectural Health and Nutrition Survey 2016. Available online: https: //www.pref.aomori.lg.jp/soshiki/kenko/ganseikatsu/files/H28_kenmin_eiyou_tyousa_01.pdf (accessed on 28 August 2018).

16. Ikeda, N.; Takimoto, H.; Imai, S.; Miyachi, M.; Nishi, N. Data Resource Profile: The Japan National Health and Nutrition Survey (NHNS). Int. J. Epidemiol. 2015, 44, 1842-1849. [CrossRef] [PubMed]

17. Ministry of Education, Culture, Sports, Science and Technology, Japan: Partial revision of Criteria for Provision of School Lunches. 30 January 2013. Available online: http://www.mext.go.jp/b_menu/hakusho/nc/ 1332086.htm (accessed on 20 December 2018). (In Japanese)

18. Resources the Council for Science and Technology Ministry of Education, Culture, Sports, Science and Technology, Japan. Standard Tables of Food Composition in Japan 2010; Official Gazette Cooperation of Japan: Tokyo, Japan, 2010; pp. 1-510.

19. Oliveria, S.A.; Ellison, R.C.; Moore, L.L.; Gillman, M.W.; Garrahie, E.J.; Singer, M.R. Parent-child relationships in nutrient intake: The Framingham Children's Study. Am. J. Clin. Nutr. 1992, 56, 593-598. [CrossRef] [PubMed]

20. Service, C.; Grimes, C.; Riddell, L.; He, F.; Campbell, K.; Nowson, C. Association between parent and child dietary sodium and potassium intakes as assessed by 24-h urinary excretion. Nutrients 2016, 8, 191. [CrossRef] [PubMed] 
21. Gauthier, H.; Timothy, S.; Frank, F. Are parents investing less time in children? Trends in selected industrialized countries. Popul. Dev. Rev. 2004, 30, 647-672. [CrossRef]

22. Flagg, L.A.; Sen, B.; Kilgore, M.; Locher, J.L. The influence of gender, age, education and household size on meal preparation and food shopping responsibilities. Public Health Nutr. 2014, 17, 2061-2070. [CrossRef]

23. Harnack, L.; Story, M.; Martinson, B.; Neumark-Sztainer, D.; Stang, J. Guess who's cooking? The role of men in meal planning, shopping, and preparation in US families. J. Am. Diet Assoc. 1998, 98, 995-1000. [CrossRef]

24. Devine, C.M.; Farrell, T.J.; Blake, C.E.; Jastran, M.; Wethington, E.; Bisogni, C.A. Work conditions and the food choice coping strategies of employed parents. J. Nutr. Educ. Behav. 2009, 41, 365-370. [CrossRef]

25. Vepsäläinen, H.; Nevalainen, J.; Fogelholm, M.; Korkalo, L.; Roos, E.; Ray, C.; Erkkola, M. DAGIS consortium group. Like parent, like child? Dietary resemblance in families. Int. J. Behav. Nutr. Phys. Act. 2018, 15, 62. [CrossRef]

26. Mennella, J.A. Ontogeny of taste preferences: Basic biology and implications for health. Am. J. Clin. Nutr. 2014, 99, 704S-711S. [CrossRef] [PubMed]

27. Bouhlal, S.; Chabanet, C.; Issanchou, S.; Nicklaus, S. Salt content impacts food preferences and intake among children. PLoS ONE 2013, 8, e53971. [CrossRef] [PubMed]

28. Kim, G.H.; Lee, H.M. Frequent consumption of certain fast foods may be associated with an enhanced preference for salt taste. J. Hum. Nutr. Diet 2009, 22, 475-480. [CrossRef] [PubMed]

29. Stein, L.J.; Cowart, B.J.; Beauchamp, G.K. The development of salty taste acceptance is related to dietary experience in human infants: A prospective study. Am. J. Clin. Nutr. 2012, 95, 123-129. [CrossRef] [PubMed]

30. Lioret, S.; McNaughton, S.A.; Spence, A.C.; Crawford, D.; Campbell, K.J. Tracking of dietary intakes in early childhood: The Melbourne InFANT Program. Eur. J. Clin. Nutr. 2013, 67, 275-281. [CrossRef] [PubMed]

31. Ministry of Education, Culture, Sports, Science and Technology. Annual Report of School Health Statistics Research. Available online: http://www.mext.go.jp/component/b_menu/other/_icsFiles/afieldfile/2018/03/26/ 1399281_01_1.pdf (accessed on 18 September 2018).

(C) 2019 by the authors. Licensee MDPI, Basel, Switzerland. This article is an open access article distributed under the terms and conditions of the Creative Commons Attribution (CC BY) license (http://creativecommons.org/licenses/by/4.0/). 